\title{
Systemic Workplace Barriers for Academic Librarians with Disabilities
}

\section{Joanne Oud}

\begin{abstract}
Although studies related to diversity within librarianship as a profession are increasing, few have examined librarians with disabilities-and none so far have included their voices or perspectives. This qualitative study involved interviews with ten academic librarians with disabilities in Canada. With a grounding in the social model of disability, it examines their workplace experiences and concerns and the barriers they face within the context of cultural assumptions about disability and work, finding that the major barriers encountered are lack of awareness of disability issues and negative cultural stereotypes of disability.
\end{abstract}

Recent years have seen an increased awareness of the need for greater diversity and equity within the library profession. In the United States and Canada, this awareness has focused primarily on the relatively homogenous racial composition of the librarian workforce. Library associations, especially in the United States, have created programs and scholarships to encourage greater racial diversity in the profession, emphasizing equity as a core value, and have announced recent equity and inclusion initiatives. ${ }^{1}$ An emerging research literature has also begun to explore the marginalization of visible minority librarians, and the barriers to inclusion within the profession. ${ }^{2}$ The emerging professional discourse and research on visible minority librarians indicate a growing awareness of equity issues within librarianship.

Less attention, however, has been focused on other minority groups within librarianship; as a result, the concerns of those groups are less well understood. Librarians with a disability are an example of such an overlooked group. Librarians with disabilities form a substantial minority within librarianship, with estimates of 3.7 percent in the United States and 5.9 percent in Canada. ${ }^{3}$ However, disability is seldom included in professional programs or discussions on diversity. There are no disability-related groups or programs within major Canadian or American professional organizations, and almost no substantial research on disability in librarianship has been carried out.

Like other minority groups, librarians with disabilities may face equity concerns within the profession. Although legal protections at the federal level and at either the state level in the United States or provincial level in Canada prohibit discrimination and guarantee accommodation for employees with disabilities, these legal protections are problematic in practice. In the United States, 93 percent of workplace-related court decisions are won

\footnotetext{
* Joanne Oud is a Librarian in the Wilfrid Laurier University Library; email: joud@wlu.ca. (02019 Joanne Oud, Attribution-NonCommercial (http://creativecommons.org/licenses/by-nc/4.0/) CC BY-NC.
} 
by employers unwilling to accommodate or hire employees with disabilities, ${ }^{4}$ partly due to the narrowness of the legal definition of disability. ${ }^{5}$ Canada's laws are, on the surface, more inclusive and disability-friendly, and employment cases have been more positive for people with disabilities. ${ }^{6}$ Despite this, the Canadian Human Rights Commission reports that more than 50 percent of its complaints are related to disability-related discrimination and that 84 percent of those are workplace-related. ${ }^{7}$ These figures are reinforced by a substantial body of research in the sociological and employment literature that documents the difficulties faced by people with disabilities in the workforce. ${ }^{8}$ Both the volume of human rights complaints and the research indicate that laws have been only partially successful at addressing discrimination and that significant equity issues still exist for people with disabilities at work.

Based on this evidence, it seems reasonable to assume that librarians with disabilities will also face equity issues at work. Since little is known about the experiences of librarians with disabilities, work needs to be done to discover what equity issues might exist and how best to address them.

This study seeks to remedy this lack of attention by exploring the workplace experiences of librarians with disabilities working in university libraries in Canada. Its goal is to broaden understanding of an overlooked minority group in the profession and to discover what, if any, equity issues librarians with disabilities face at work. Based on a theoretical framework used in disability studies, this study is situated within the context of existing research on the issues encountered by employees with disabilities in other work environments. It aims to discover more about the work experiences of university librarians with disabilities in Canada, to identify the underlying structural issues and barriers within the workplace that create difficulties for this group, and to explore how similar these experiences are to those reported in other types of workplaces.

\section{Literature Review}

Although no equity-related research on librarians with disabilities currently exists, several research studies do highlight workplace equity problems and issues for racialized or visible minority librarians. Some of these important studies examine the equity issues related to job structures and processes, including interviewing and hiring, ${ }^{9}$ tenure and promotion, ${ }^{10}$ succession planning, ${ }^{11}$ and management. ${ }^{12}$ Others explore challenges faced by visible minority librarians in the workplace, including limited access to networks and support as well as less frequent leadership opportunities. ${ }^{13}$ Studies also show that racialized or visible minority librarians often feel that they aren't accepted as equals, feel isolated and excluded, ${ }^{14}$ and lack role models and support networks. ${ }^{15}$ Research has documented incidents of discrimination and harassment, ${ }^{16}$ including microaggressions, or everyday interactions that communicate negative messages about race. ${ }^{17}$ Other studies have indicated that internalized stigma, stress, and self-doubt are common for racialized or visible minority librarians. ${ }^{18}$

An increasing number of these studies use a critical race studies framework, examining or calling for greater attention to the underlying structural mechanisms within libraries and librarianship that create or perpetuate racial discrimination. These studies show how the structural underpinnings of libraries are based on assumptions of whiteness, and they argue that achieving inclusion requires a focus on the systemic practices and mechanisms of discrimination in libraries, not just on increasing numbers of minority librarians. ${ }^{19}$ This emerging body 
of work plays an important role in drawing attention to the sometimes negative workplace experiences of racialized or visible minority librarians, and to the mechanisms of structural inequality within the profession of librarianship.

These mechanisms of structural inequality are likely to extend beyond issues of race. People with disabilities are also a potentially disadvantaged minority group within the profession. However, much less research exists on equity issues related to disability within librarianship. Disability is present within the existing library literature, but it has generally been discussed in a narrow and specific way that emphasizes library services to patrons with disabilities. A recent content analysis of library literature on accessibility and disability finds that nearly all existing studies focus on patrons with disabilities and library services meant for those patrons, with a strong emphasis on the accessibility of electronic resources and websites; little deals with attitudes and perceptions of disability or involves people with disabilities directly. ${ }^{20}$

A few existing studies do mention librarians with disabilities, and those studies suggest some workplace equity issues. O'Neill and Urquhart examine the perceptions of library managers regarding accommodations for employees with disabilities, finding that managers are reluctant to make accommodations related to changes in work patterns, such as flexible hours. ${ }^{21}$ Brown surveyed public library employee attitudes to having people from underrepresented groups as colleagues and found that people showed unconscious bias toward librarians who were nonwhite or disabled. ${ }^{22}$ Johnstone examines Australian policy on workplace-related disability and finds a general lack of understanding of disability, including incorrect assumptions about the cost and nature of accommodations. ${ }^{23}$ Although these studies show some potential problems and attitudes faced by librarians with disabilities, they do not involve librarians with disabilities or take their perspective.

A handful of publications in the library literature attempt to document the perspectives of librarians with disabilities. In the earliest, Warren surveys 42 librarians with disabilities and discovers workplace barriers that include physical workplace inaccessibility and difficulties finding jobs. ${ }^{24}$ Warren's work is the only research study involving librarians with disabilities, but the study is 40 years old and considerably out of date. Other articles that include the voices of librarians with disabilities are short, informal personal accounts, including Ziglar's personal experiences as a librarian in a wheelchair, ${ }^{25}$ Barlow's discussion of the experiences of a few librarians with disabilities based on personal conversations with them ${ }^{26}$ and Sager's column featuring the personal accounts of some librarians with disabilities ${ }^{27}$ These accounts provide some insight into the experiences of librarians with disabilities and highlight some barriers, especially in finding employment. However, none are recent, and as informal personal accounts, they are not situated within a broader analysis of the systemic issues that impact the experiences of people with disabilities in the workplace, limiting their usefulness in identifying equity issues.

A recent article on disability in libraries is the first to adopt a broader perspective on the structural issues underlying the experience of disability in libraries. Kumbier and Starkey use a critical disability studies perspective to discuss accessibility and disability as issues of social justice in libraries. ${ }^{28}$ They argue that existing library literature on accessibility assumes that disability is a problem to be solved; it focuses on legal compliance and individual accommodations to solve this problem instead of investigating the underlying structures that create barriers to access for people. They comment, "if we... do not consider how to change 
the terms of access to the profession or the way we think about disability in the profession, we will not get beyond the 'tick-box' approach to realizing our professional values of access and equity." ${ }^{29}$ Kumbier and Starkey lay important groundwork in examining disability in librarianship from a more critical, structural perspective based on disability studies research and theory.

Although rare in librarianship, a substantial body of literature exists within disability studies that looks at the workplace experiences of employees with disabilities from a critical perspective similar to Kumbier and Starkey. This literature uses theory from disability studies, especially the social model of disability and the concept of ableism, ${ }^{30}$ to critically examine the systems, structures, and social attitudes that create difficulties or barriers for people with disabilities in the workplace. Many of these barriers relate to negative social and cultural attitudes toward disability. Several studies find that negative cultural stereotypes equate disability with lower productivity, which disadvantages people with disabilities in hiring and creates difficulties for them on the job. ${ }^{31}$ Studies find that even when employers report positive attitudes to disability, these attitudes tend not to translate into willingness to hire and accommodate employees with disabilities. ${ }^{32}$

Only a few studies explore the work experiences of professionals with disabilities, but structural and attitudinal barriers for these groups appear to be similar to those already discussed. Studies of professional accountants, lawyers, and university employees all find that major workplace barriers include the invisibility of disability at work, a lack of understanding of disability, and stereotypical views of people with disabilities as less capable workers, leading to both overt and subtle forms of discrimination. ${ }^{33}$

As a result of these negative views of disability, people with disabilities face a range of equity issues at work. Studies show that the stereotype of people with disabilities as less competent leads to a range of behaviors that marginalize them in the workplace, including harassment and discrimination but also including lower levels of access to training, less involvement in decision making, and lower promotion rates. ${ }^{34}$ People with disabilities also encounter difficulties gaining access to the workplace accommodations that they are legally entitled to. Some studies find that the fear of negative work impacts such as being seen or treated differently, fired, or not promoted are important barriers to people disclosing their disability at work. ${ }^{35}$ Studies also find that employers often discourage people with disabilities from asking for accommodation at work through a variety of obvious or subtle means; if people with disabilities do request accommodation, they are relatively frequently turned down or not taken seriously, sometimes accused of faking, complaining, or abusing the system. ${ }^{36}$ As a result, people tend to resist asking for accommodation unless absolutely necessary.

The disability studies literature and the library literature on diversity both suggest that librarians with disabilities are likely to encounter barriers at work. However, these literatures do not intersect: the disability studies literature on work does not consider librarianship, and the library literature does not critically examine workplace experiences of disability. This study is intended to begin to fill this gap in both literatures. It takes a small step toward bringing the workplace experiences of academic librarians with disabilities into clearer view. It uses a critical framework grounded in disability studies and investigates the difficulties or barriers, and the structures and attitudes underlying those barriers, for academic librarians with disabilities in Canada. 


\section{Theoretical Framework: Disability Studies and Work}

This study is based on a theoretical framework from disability studies that is grounded in concepts including the social model of disability, ableism, and the historically based assumptions about disability and work. In this framework, social assumptions about disability and about the characteristics of an ideal worker combine to influence the workplace experiences of people with disabilities.

The social model of disability is a foundational concept in disability studies, created by disability activists in the 1960s and 1970s and given a name by British scholar Mike Oliver in $1983 .{ }^{37}$ The social model of disability views disability as a form of social oppression, like racism or sexism. In this view, the concept of impairment or physical limitation is separated from the concept of disability. ${ }^{38}$ Disability is a social and cultural construct, created when someone encounters a barrier in their environment that makes it difficult for them to function "normally." ${ }^{39}$ In the social model, disability is caused by aspects of society that create difficulties for people, including physical, cultural, and attitudinal barriers, rather than by an individual's impairment. Disability studies scholars examine these barriers along with how people internalize them and create strategies to overcome them.

Along with the social model, a key underpinning of disability activism and scholarship is the concept of ableism. Ableism refers to the cultural assumption that everyone is ablebodied. Social structures and organizations are based on this assumption, and everyone is judged against this able-bodied norm, which means that people who aren't able-bodied are seen as inherently inferior. ${ }^{40}$

Ableism and the social model of disability have only made minor inroads into mainstream public perception. The prevailing cultural view of disability is called the medical, individual, or deficit model in disability studies. In this view, disability is a personal misfortune, an individual medical problem or deficiency that needs to be fixed to make the person "normal."41 No one would be happy to have a disability in this view - having a disability means that there is something wrong with you, and this is always worse than not having one. When judged against the cultural assumption of able-bodied as "normal" people with disabilities are found to be less than normal, and disability is, therefore, seen as inherently negative and inferior. ${ }^{42}$ The medical model of disability disadvantages people with disabilities not only because it assumes they are flawed and inferior, but because its focus on individual medical issues and accommodations obscures and directs attention away from the broader structural assumptions and practices that create difficulties and barriers.

Disability studies research also makes clear that perceptions of ability and disability are strongly linked to the structure and assumptions of work. Scholars have outlined how the current mode of work is interconnected with assumptions inherent in the medical model of disability. The category of disability as we know it was created as part of the shift to an industrial, capitalist workplace, and it described people who couldn't keep up with the demands of the new mode of work, including production quotas, time schedules, and standardized ways of performing tasks. ${ }^{43}$ In this way, work organizations were built on the premise of "ableness," excluding those who were less "able." Historically, disability has been equated with inability to work.

These historical assumptions have carried forward into the contemporary workplace. Disability studies scholars have found that ableness tends to be defined at work as "what it takes to get the job done," which is based on assumptions of able-bodiedness. ${ }^{44}$ These as- 
sumptions have intensified in the current neoliberal economic context with its focus on competition, which translates in the workplace to an increasing focus on measurable employee productivity and efficiency. ${ }^{45}$ Studies have shown higher employer expectations of "energy, speed, stamina, flexibility, and productivity among workers." 46 These increased expectations have not been positive for people with disabilities, who tend to be viewed as less productive and capable and, consequently, as less competitive in the workplace. ${ }^{47}$ Therefore, there is an inherent tension between the concept of the ideal, productive, competitive worker and the concept of people with disabilities as inherently less productive and competitive.

This tension serves to marginalize people with disabilities in the workforce. Disability studies scholars have found that, culturally, "bias and stereotypes of disability as lower productivity, incompetence, helplessness and dependency persistently disadvantage workers in selection processes and hamper their social acceptance by others when employed." 48 In Canada, for example, 49 percent of people with disabilities are employed, compared to 79 percent of people without disabilities. ${ }^{49}$ Among university graduates, the picture is only somewhat better. University graduates with disabilities have twice the unemployment rate of those without disabilities, earn less money, and are more likely to work part-time. ${ }^{50}$

The disability studies research, then, uses the theoretical concepts of the social model and ableism to explore the experiences of people with disabilities at work, the social and other structural barriers they encounter, and the impacts of those barriers. This study is informed by the same theoretical framework and methods to examine the library workplace context, which has been little explored from this perspective.

\section{Method}

This study was conducted through interviews with ten librarians with disabilities working in university libraries in Canada. No specific definition of disability was used for the study. Both in a survey and in interviews, participants were left to decide whether they had a disability according to their own definition. This was a purposeful decision that reflects the difficult and political nature of definition within disability studies. Disability studies theorist Susan Wendell summarizes these difficulties, claiming that "defining disability and identifying individuals as disabled are... social practices that involve the unequal exercise of power and have some major economic, social, and psychological consequences in some peoples' lives." 51 She argues that the people who most often define disability are service providers rather than people with disabilities themselves, which means that "the power to define is not necessarily in the hands of those who are most affected by the definitions." 52 Therefore, rather than imposing a definition in this study, participants were given the ability to self-identify based on their own definition of disability. Interviewees reported a range of disabilities, including mental health disabilities, anxiety, ADHD, hearing-related disabilities, mobility-related disabilities, and chronic illnesses such as type 1 diabetes and pain disorders. Nine of the ten participants reported invisible disabilities and one reported a visible disability.

The study takes a naturalistic, qualitative approach, ${ }^{53}$ based on semistructured interview questions. Questions were developed based on major themes found in the disability studies literature on work, including relationships with colleagues and supervisor, workplace barriers or difficulties, and strategies for dealing with them. Questions were purposely designed to be broad enough to elicit a wide range of possible responses from participants and to avoid reflecting the researcher's biases and assumptions. 
Interviewees were recruited as part of a separate study involving an online survey on job perceptions of academic librarians with and without disabilities. This survey was sent to all librarians working in Canadian university libraries in October 2016. The survey included questions on work satisfaction and diversity climate in the workplace for all respondents. Those who identified themselves as people with disabilities were asked additional, disability-specific questions. These included disclosure of disability to colleagues and supervisor, accommodation requests, coping strategies on the job, and perceptions of barriers at work. They were asked if they would be willing to participate in an interview for this research study.

Those who agreed to participate in an interview were sent details of the interview project, including its goals, methods, measures taken for confidentiality and anonymity, and a copy of the interview questions. Ten people agreed to be interviewed. Participants were located across Canada. All identified as female and held permanent or tenure-stream positions. Two were in management or supervisory positions, and four also belonged to another minority group. Participants were located geographically in five Canadian provinces. Half had fewer than ten years of experience and half had more than ten. Nearly all had liaison duties including aspects of collections, reference, and instruction, with some work in technical services and archives.

To be responsive to accessibility needs, interviewees were given a choice of interview mode. Interviews took place by phone, Skype, and in person, during November 2016. Interviews ranged in length from 30 to 45 minutes. Saturation or redundancy sampling was used; after ten interviews, similar themes emerged with each interview, and data saturation was judged to have been reached.

Interviews were transcribed verbatim with minor modifications to remove filler words like "um," then coded using the two-stage coding process outlined by Saldana. ${ }^{54}$ First-stage coding involved assigning initial codes, including structural or descriptive codes to summarize content, concept, or analytic codes to summarize "big picture" ideas or meanings, emotion codes to indicate feelings, and value codes to indicate values, attitudes, and beliefs. Multiple rounds of coding were done to assign different types of codes, and a code book was created. In addition, a code-recode process was used to validate initial coding. After a number of weeks, initial coding was done a second time without checking the first coding, then results were compared. The second cycle of coding involved looking at code frequency and logically grouping initial codes into clusters based on common themes and concepts. After a number of weeks, second cycle codes were also recoded to validate initial themes and clusters. Results were compared with initial themes, and modifications were made where needed. Analysis was done using different groupings of participants (for example, comparing interviewees with mental health-related disabilities to those with other disabilities), but no differences in themes emerged by group.

A variety of standard qualitative research techniques were used to assist in the rigor, credibility, and dependability of the study. ${ }^{55}$ One strategy was to use the code-recode and two-stage data analysis methods discussed previously, to ensure dependable data analysis. Another was participant validation, sometimes called member checks. Participant validation was used at two stages. After interviews were transcribed, participants were sent the transcript and asked for feedback. Most responded with changes and corrections, which mainly consisted of additions to what they had said or clarification of what they had meant to say. After second-stage coding, participants were sent major interview themes and given an opportunity to offer comments or feedback, which were incorporated into the analysis. 
In addition, results were triangulated in various ways. As already mentioned, data were examined in different ways using different groups to ensure that themes or contradictions were not missed. Results were also triangulated with theory, including existing disability studies theory and research and diversity-related research in librarianship, to check for consistency. Finally, interview themes were compared with responses to the disability-specific questions from the survey, both with and without inclusion of data from interviewees. A high level of overlap between survey results and interview themes was found, indicating a level of validity and dependability of interview results.

Since this study takes a naturalistic, qualitative approach, the focus in reporting results is on the nature and character of interview responses rather than a quantitative or numerical analysis of them. The assumptions behind this approach are that generalizations are not possible, but that research can create understandings within a specific context. ${ }^{56}$ In this approach, the unique experience of a single participant is as important as the common experience of several participants. The goal is to understand each participant's experience specifically along with the range of similar or different experiences. ${ }^{57}$

When reporting the findings of interview studies, a common practice is to create a profile for each interview participant, assign them a pseudonym, and identify each quote with that pseudonym. This practice does help the reader form a clearer picture of each interview participant and adds greater context. It has not, however, been used in reporting results from this study. Since disability carries the weight of potential negative social stigma, several study participants expressed particular concern for confidentiality and anonymity. Allowing readers to determine which quotes belong to a particular participant, even with a pseudonym, is potentially identifying for participants. Therefore, results are reported without identification to protect participant confidentiality.

\section{Findings}

Academic libraries have been experiencing increasing pressure to do more with less and provide evidence of value - in short, to conform to neoliberal ideals of competitiveness, productivity, and efficiency. This pressure creates tension with the traditional values and roles of academic librarianship, which emphasize helping, a service culture, and a traditionally flexible professional work environment. This tension was evident in the interview responses. On the one hand, librarians with disabilities reported a wide range of difficulties associated with cultural assumptions about disability and the competitive workplace. On the other hand, librarians with disabilities also commented frequently on a positive workplace culture, associated with the characteristics of traditional library values. These findings will be reported in three sections. The first section will explore the cultural assumptions about disability and work that help create workplace issues or barriers for academic librarians with disabilities. The second section will discuss the implications and impacts of those barriers for librarians with disabilities in the workplace. Finally, the third section will examine the positive workplace experiences reported by librarians with disabilities, and the workplace features that help facilitate them.

\section{Structural Workplace Barriers}

Nearly all interview participants reported negative work experiences related to cultural assumptions about disability and the pressures of an increasingly performance-oriented 
workplace. Findings indicated that the two main issues causing difficulties for librarians with disabilities are a lack of awareness or misunderstanding of disability and various assumptions about and structures of the work environment.

\section{Attitudes to and Misunderstanding of Disability}

One of the key barriers mentioned was a lack of awareness of disability-related issues. Most interviewees commented that even when their colleagues and supervisors were sympathetic and well-meaning, they often lacked a basic understanding of disability. Interviewees frequently mentioned the general lack of awareness of disability-related issues at work. As one commented, "A lot of my problems were related to the indifference or ignorance about disability. I think there's a lack of understanding of what disability actually does and what kinds of limitations that you are confronted with." Another said, "I don't think that people don't care or they're not supportive, they're just not aware because if you don't face the barriers, if you don't experience them directly they are invisible to you."

Many participants also commented on a lack of awareness of the issues they faced due to their specific impairment. Although disability studies scholars have found many commonalities in the treatment of people with disabilities at work, people with disabilities are not a homogenous group. Disability is experienced individually, through the lens of a specific impairment. This was evident in the interviews, where participants commented on colleagues' ignorance of issues related to their impairment. As one participant with type 1 diabetes says, "I do get the usual 'stupid' comments from colleagues such as 'oh I didn't think you could eat cake'... it's annoying and I usually try and explain about how diabetes treatments have progressed since 1921. I guess I know it comes from a good place but it's still annoying." Although people with the same type of disability can have different degrees and types of impairment, some participants mentioned that coworkers assumed everyone with a certain type of disability must all be the same. One discussed how her colleagues were impatient with her because she couldn't hear as well as another colleague who also had hearing loss: "There was another librarian who was also hard of hearing, but she was less hard of hearing than I was and coped extremely well. In a way that was a disadvantage for me, because it was 'well, she's hard of hearing and she can get everything."'

One component of this lack of understanding of disability issues seems to be a misunderstanding of what disability is. Several interviewees commented that their workplaces had a narrow and ill-informed view of disability. One, speaking about a manager, said "It became clear to me that she had a very narrow definition of disability... she was thinking about wheelchair users, people with mobility impairments, people with vision impairments, deaf people. Very traditional, classic disabilities." Although far more disabilities are invisible than visible, several interviewees commented that people seemed to feel that the only "legitimate" disabilities were visible ones. This misconception can be explained by disability studies theory: the standard cultural assumption is that everyone is able-bodied, and people with invisible disabilities appear on the surface to be able-bodied, making it more difficult to accept that invisible disability is genuine or equivalent to visible disability.

This misunderstanding of disability may render disability invisible in the workplace. Multiple participants commented that colleagues and supervisors assumed that everyone in their workplace was able-bodied, which had the effect of rendering disability invisible. Others mentioned that since their colleagues and supervisors assumed there were no people 
with disabilities in their workplace, they therefore felt that they didn't need to engage with or learn about disability issues. As one participant with an invisible disability said, "That's another kind of erasure of people with disabilities. It's easy not to think about it because there isn't anyone they know of in the system."

The misunderstanding of disability, especially of invisible disabilities as not "legitimate" disabilities, also led to negative judgments and stereotypes of being lazy or not wanting to work. Multiple participants reported negative stereotypes of laziness related to disability in their workplace. One, reporting on a conversation with someone in a senior management role, said, "Her comments gave me the impression that she was dismissive of invisible disabilities, as though they weren't legitimate but were excuses for laziness." Another participant said, "There was an assumption that if somebody says 'I need accommodation' that the person is lazy or doesn't want to work."

Another negative stereotype reported by participants was that people with disabilities are trying to ask for special treatment. The disability studies literature commonly reports this misconception of "gaming the system" for unfair advantage, especially in relation to requests for workplace accommodation. ${ }^{58}$ Workplace accommodations are meant to level the playing field for people with disabilities and help them cope with the workplace barriers they face, but they are frequently misinterpreted by those who don't understand those barriers as special treatment or trying to manipulate the system to gain some unfair advantage. This misconception, by both coworkers and supervisors, was mentioned by several interviewees. One, discussing her unsuccessful request for accommodation, said that the management response was "If I let you do it, I have to let everybody else do it," misunderstanding the nature of accommodation as leveling the playing field for people with limitations due to their disability. Another participant expressed frustration at some colleagues who equated accommodation with receiving special treatment:

It might look like a perk, but you don't really want what goes along with it. When people see accommodation there is a lack of understanding of what the reality of the disability might be. They think you want special treatment, but really I need this to get through the day or navigate the barriers I face every day that you never have to think about. If you want to trade, I'm happy to... They say they want that too. Oh really? Look what you've won.

Librarians with disabilities also reported facing judgments based on how far from "normal" or able-bodied they are. In some cases, participants reported being judged on their ability to hide or overcome the effects of their disability, something that is usually not under their control. One interviewee mentioned a colleague's comparison of her with another diabetic: "They did say mostly negative things, like 'she was out of control.' It's just one colleague who said that. I'm not exactly sure what that meant, 'out of control.' I guess it wasn't a positive thing to experience. The idea that there are good diabetics and bad diabetics, which is often how diabetics are viewed."

Participants with invisible disabilities tended to report more negative judgments and suspicious reactions to their disabilities. In particular, participants with mental health disabilities were aware of facing a high level of stigma. As one mentioned, "Everyone always says 'let's talk about mental health' but no one ever does. When you do talk about it people 
get super awkward and don't know how to respond." Another commented, "If it's mental health related I think people are a lot more careful, a lot more cautious and uncomfortable."

\section{Competitive Workplace Assumptions}

Along with cultural attitudes and lack of understanding of disability, a significant barrier reported by librarians with disabilities relates to some of the characteristics of the increasingly competitive, neoliberal workplace environment. Major themes from the interviews that illustrate this barrier included increasing assumptions of high productivity and a quick pace of work.

Interviewees frequently discussed concerns about productivity and workload. Doing more with less creates potential difficulties for all workers but can cause particular difficulties for people with disabilities who need to use different strategies or take more time to complete their work. As one interviewee commented, "I feel there's quite a lot of pressure to do work or to do certain types of work, and certain types of work are valued differently. That makes it a tough situation for anyone, and maybe for me with a learning disability... because I feel it takes me longer to do things than everyone else I feel it would be nice if there was less workload." Another discussed how she is aware of the stereotype of workers with disabilities as less productive; as a result, she worries about her productivity compared to colleagues: "It's very important to me that I do as much work as my colleagues. And yet I have physical limitations that I need to work around. So I think it's always a challenge of am I doing as much work. I've come to the conclusion that I do, I just do it differently. I need to do it differently so therefore it's harder to compare." She explained how colleagues have sometimes judged her negatively for her productivity because she needs to take a different approach to her work: "I think there have been moments where some colleagues wondered if I was contributing as much or working as hard as I could. But then when I revealed a little more about why I was doing it differently that kind of gets rid of that a little bit. So you do run into that."

Several interviewees mentioned difficulties in dealing with work expectations around speed and turnaround time, including quick decision-making and inadequate time to prepare in advance. One participant with a hearing-related disability, who reported difficulties following quick conversations in meetings, discussed her challenges with the expectations of immediate decision-making in her management-level position: "At that level, unfortunately, one of the things that seems to be valued is the ability to think really quickly and respond really quickly. So people would have a really fast conversation and want a decision immediately. And that's a bit difficult." A participant with a learning disability also discussed having difficulty with quick decisions and responses: "I have a hard time formulating responses when I'm put on the spot." Another interviewee discussed her need to prepare well in advance as a strategy for managing her anxiety, expressing frustration with a former colleague who didn't allow her that time even after explanations and repeated requests: "I would ask 'ok what am I doing?' two weeks beforehand .... and then he'd never get back to me about it... It would get closer and closer to the time and I said 'you have to tell me what I'm doing because I need to prepare well in advance, because I can't do it off the cuff.' So he wouldn't help in that regard."

\section{Work Structures}

For some librarians with disabilities, barriers are created by workplace structures that might appear normal or unproblematic for people without disabilities. Major themes dealing with 
issues of workplace structure include dealing with work structures that create conflict and ambiguity, and the lack of structural supports for disability.

Some participants reported that ambiguous work structures created difficulties for them. In particular, a few participants with mental health-related disabilities reported that the conflict and stress created by ambiguity and lack of clear priorities at work made it challenging for them to cope at work or contributed to the worsening of their disability. One discussed how difficult it was for her to work in an environment where she is expected to determine her own priorities even though the organizational goals and priorities are conflicting and unclear: "Everybody seems to have different ideas about what should be valued... and that can be problematic." Another participant described considerable work stress arising from an unsympathetic supervisor and from a matrix reporting model with multiple supervisors who don't agree. She described how difficult it was for her to feel caught in the middle of this type of conflict, explaining how dealing with the stress from this situation has contributed to her disability over the past few years:

In the right circumstances, I'm very capable and I can work a full week and do an excellent job with no difficulty... Mine is more of a mental health situation, so for me this type of environment, it makes me ill. My feeling is that a few years ago no one would have called me disabled, and I wouldn't have thought of calling myself disabled. I've always had some challenge in some areas but I wouldn't have thought of it that way. But over the past few years, with the workplace and how it contributes to my situation I think I've become someone who is now a disabled person.

This concept of disability being worsened or created by certain conditions is also found in disability studies research; disability theorist Susan Wendell explains it as "the social construction of disability through the expectations of performance." ${ }^{59}$ In the social model of disability, disability is contextual: it is created when people encounter situations that create difficulties for them, like a wheelchair user encountering a set of stairs rather than a ramp. This concept also applies to the workplace: people with disabilities may be able to function "normally" under certain conditions, such as a certain level of stress, amount of workload, or number of hours in a week, but not if those conditions change. In this participant's case, when the ambiguity, conflict, and work stress increased, they created conditions where she could no longer work as effectively, contributing to her disability.

The absence of workplace structures and processes, especially those related to ensuring a positive environment for employees with disability, also created barriers for librarians. Participants were most concerned about the absence of structures related to supervisor training and support. Interviewees often explained that a positive workplace was dependent on having a good interpersonal relationship with an individual supervisor; supervisors were not trained to be good managers, have an understanding of disability, or to provide appropriate support to librarians with disabilities. As one participant commented, "My feeling is that it's the luck of the draw whether you get to have a decent manager or not, and it shouldn't be. There should be some appropriate oversight of managers and training, somewhere you can go to get the support that you need, and I don't feel that that's there."

Since knowledge of and support for disability in supervisors varied considerably, some interviewees expressed concern about how precarious their current positive work environment 
was and how that might change if their supervisor changed. One who had experienced a positive environment under a former supervisor worried about how a new, incoming supervisor would react to learning about her disability. Another worried about the potential impact on her career and job environment if her current situation changes:

I'm in a very good position right now, and we've got a really supportive supervisor and supportive coworkers, but I've been around long enough and been in enough workplaces to know that nothing's permanent. What would happen if that changed? And would people think I was trying to get out of certain activities... In those frustrating moments when I know it's deteriorating a little faster, I can't help but give into that fear and go after those 'what-ifs' and pursue the down the rabbit hole. That's not really something that's productive. But I can't help it, I feel it.

Although the lack of structures related to supervisor support caused the greatest concern, participants mentioned other workplace structures that were problematic from a disability support perspective. One commented on the lack of structures and processes in place in her workplace to deal with any problems encountered due to disability: "If I did feel discriminated against it's hard to know what to do about it." Others commented on previous workplaces without policies or trained staff who could deal with workplace accommodations.

\section{Impacts and Implications of Barriers}

These barriers have impacts on academic librarians with disabilities in the workplace. The lack of awareness and cultural stereotypes of disability, in particular, have implications for how librarians with disabilities experience their workplace and interact with their colleagues and supervisors. The three most common impacts reported by interviewees were: 1) having to deal with colleague and supervisor discomfort with their disability; 2) reluctance to discuss or disclose their disability at work; and 3) reluctance to ask for workplace accommodation even though they are legally entitled to.

\section{Discomfort with Disability}

Participants frequently mentioned that colleagues, supervisors, and library patrons had uncomfortable reactions to their disability. Other peoples' discomfort was commonly mentioned, and many participants discussed incidents where other people were uncomfortable when confronted with their disability. One, who has hearing loss, explained: "I disclose it right off the bat if I'm struggling at all or if I'm in a situation where I think it's going to be a problem. Sometimes people seem quite uncomfortable...but we just figure it out and I don't take it too personally." Another participant, who is comfortable discussing her mental health disability openly, explained that she frequently needs to reassure other people because they are less comfortable: "Other people seem to be uncomfortable talking about it or don't know how to respond... I always try to be like 'oh, it's totally fine, I don't mind talking about it.'"

Related to this discomfort with disability, participants also discussed incidents where their disability was minimized or their contributions were diminished because of their disability. Participants talked about how others at work sometimes dismissed the severity or legitimacy of their disability or their experiences with their disability. As one interviewee with an anxiety disorder said of a colleague, "He said he understood, but at the same time 
there was a feeling of 'yeah, I get panic attacks too, suck it up.' And I don't think that's how he felt, but that's what it felt like." Some participants also discussed feeling that they were taken less seriously or underestimated because of their disability. One interviewee with a hearing impairment spoke about her difficulty keeping up in meetings, feeling that her contributions were discounted because of it: "If I did say something that had already been said or partly said it was always amusing. So I was kind of amusing rather than serious, people didn't really take my ideas seriously. I mean none of this is conscious, it's all unconscious, no one even knows they're doing it."

\section{Disclosing Disability at Work}

Given some of the negative cultural attitudes about disability reported in the previous discussion on barriers, and participants' personal experiences with others' discomfort, it is not surprising that librarians with disabilities report mixed feelings about discussing or disclosing their disabilities to others at work. Disability disclosure was frequently discussed in the interviews. Some participants decided to disclose their disabilities to others at work, either as a coping strategy or as a way to raise workplace awareness of disability. Others were reluctant to mention their disabilities due to past experiences with stigma, or fears for the potential impact on their job. The majority of participants reported disclosing a disability selectively, to only a few coworkers they trusted.

Some participants did not hesitate to disclose their disability at work. In some cases, disclosure was a way of coping, so colleagues knew what to expect and misunderstanding or negative judgments could be minimized. One participant with a hearing-related disability explained that she discloses her disability to people up front as a coping strategy: "It's got to the point now where I've started telling people at the outset that I do have hearing loss and that if I lean forward and squint a bit it's probably because I can't hear you." Another participant discussed how she discloses her disability to avoid misunderstanding, after past experiences where she was misunderstood and judged negatively when she didn't disclose her disability at work:

Yeah, everyone is aware that I'm type 1 diabetic and that's by choice but it's also by experience. I haven't always told people. I remember when I was in high school I worked in a grocery store and I didn't tell the people there that I was diabetic, and my blood sugar went low and I wasn't able to talk. So they went into my locker, and this was back in the day, before they had all the new diabetes things they have now, so I had all these syringes which I used to take my insulin and they thought I was a heroin addict [laughs]. So eventually what ended up happening is that my liver kicked in and it starts producing glucose and brought me out of the low, but they had made all these assumptions about me and my life and this kind of thing. So I learned after that that it's just better to tell people.

In other cases, people are open about their disability at work because they want to raise awareness of disability issues and help improve conditions for others. One participant spoke about how she took the risk of disclosing her disability to a manager because she wanted to improve awareness of invisible disabilities in her workplace: "I wanted to point out that you could also have invisible disabilities for example, and maybe she didn't know that she had 
employees with disabilities." Another commented on her growing willingness to be open about her disability to raise awareness of disability issues, realizing that not everyone is in a position to take that risk: "Personally I've come to the conclusion that 'passing' is bad, because then you disadvantage everybody who can't do that. So for that reason I'm still very private, but I'm loosening up about sharing certain things. Otherwise I wouldn't be doing this interview [laughs]." One interviewee with a mental health disability talks about becoming more open about her disability despite the stigma and discomfort she encounters, as a way to contribute to the mental health community and to help repay those who have helped her: "I'm not as afraid to talk about it anymore. I used to be. But I'm not as. And I just thought of it as if I talk about it, that's a way for me to pay back in a way and contribute back to the people who helped me out a lot. That's how I see it."

Although some participants chose to be open about their disabilities, several others reported reluctance to disclose their disability at work. In some cases, this resulted from negative workplace experiences they had after disclosing their disability in previous situations. One participant felt that her previous efforts to be open about her disability created difficulties for her, making her hesitant to discuss it openly again: "I'm not going to explain to anybody any more, including my supervisor. It just wasn't worth the effort. It just made it worse I think. So I just say what I need and then I don't explain any more. That can create conflicts, but trying to explain didn't work either." In other cases, people are not comfortable talking about their disability for personal reasons, especially if their disability is relatively recent. One participant explained that she initially had difficulty disclosing her disability and dealing with peoples' misunderstandings and reactions, mainly because she was still coming to terms with it herself: "I had a really hard time disclosing it when I first started dealing with it. People would invariably say 'well you're not that old.' That's not the point. This is a degenerative hearing condition that has nothing to do with age. So instead of getting mad I would just try to explain that, but at first I was embarrassed."

The most common reason participants mentioned not discussing their disability at work was that they did not feel safe doing so, or feared that it would have a negative impact on their job. Safety concerns related to disclosing their disability or asking for accommodation were frequently mentioned by participants. As one explained, "Generally speaking I have not self-identified at work. In some circles I have, but generally speaking I felt that it's not to my advantage to. Not that it should be an advantage. But it hasn't felt safe to." Often participants felt that disclosing disability at work was unsafe because it carried potential risk, most commonly involving the impact on supervisor and colleague perceptions due to the negative stereotypes involved with disability. One participant commented, "You never know how it's going to be perceived, especially if you're a new librarian, you don't want to impact your chances of success by tainting your employer's perspective." Another, who is open about her disability, talked about her concerns about the potential impact of this strategy on the perceptions or judgments of colleagues: "I try to be like 'end the stigma, talk about mental health' and I am pro that and I have no problem talking about it ...but at the same time I don't want my colleagues to see me as being lesser in some way, or being incapable of doing my job. So that's always for me kind of a fine line." Some participants feared other risks, including impact on promotion and pay increases. After disclosing her disability to a manager, one participant worried about the potential impact both on perceptions of her and on her pay increases: "I have no regrets about it, but there's always this slight question, does she [the manager] now 
think that I'm a challenging person or whatever, and is that going to be reflected in my merit increase."

Several interviewees mentioned a sense of security and trust at work as a major factor in deciding whether to discuss their disabilities openly. This sense of security involved several factors, particularly job stability, a supportive work environment, and a sense of personal confidence. One participant explained, "I feel safe in the job that I have. I have continuing appointment. I'm in an environment that's trying to be more inclusive. So I feel like I have the safety and the luxury of being able to be up front about my disability." Another commented on the difference between her previous and current jobs, and her own change in attitude, as factors that led her to be more open about her disability: "I just didn't want to have any deficits where I was before because I felt pretty unprotected, but there's a lot more security here and I think I've just become more confident as a librarian as I'm sort of hitting this mid-career portion." Conversely, participants mentioned the lack of a supportive and inclusive work environment as a major factor contributing to their reluctance to discuss their disability. One participant explained, "I have to feel like it's an open environment where I can discuss it and that discussion is welcomed, but I don't know if it is. I still don't think it is."

In many cases, participants reported disclosing their disabilities selectively at work to people they trusted and felt safe with, rather than being fully open about it. As one explained, "There's one other person ...she also has anxiety and we talk about it a lot. She's like 'you're going to be fine,' 'just take your pills,'.... lot of people say that and they don't get it, so I just get annoyed. When I have people without anxiety saying 'you'll be fine,' they don't understand what goes on. But she does. So we talk about it a lot." Another commented, "With people who I trust I will say 'I have these issues will you help me,' and then they will be very helpful. For instance I was diagnosed with ADD so I will say to someone 'you know, I have ADD, and I'm going to forget, can you remind me, and if I do forget don't take it personally, it's nothing to do with you, it's me.' So they've been very, very helpful with that."

\section{Difficulties with Workplace Accommodation}

Participants reported a similarly mixed experience with requesting legal workplace accommodation for their disability. Many participants had not requested accommodation. Those who had requested accommodation reported mixed experiences, with both positive and negative experiences and results. Most participants, however, hesitated to request accommodation for reasons similar to their hesitation to discuss their disabilities, including fear of potential negative impacts on their jobs.

Most participants preferred not to ask for legal work accommodation unless absolutely necessary, and instead to use alternate coping strategies wherever possible. As one explained, "My first strategy is always to figure out if I can figure something else out on my own and devise my own strategy to meet my needs. Only if everything I can think of fails, then I might ask for accommodation." Another spoke about her strategy of disclosing her disability only minimally at work, which has sometimes created difficulties for her when she tries to make alternate work arrangements without explaining why instead of going through the formal accommodation process: "I guess I've always self-identified just enough to explain what was going on. So it's created trouble sometimes when I've needed that slight accommodation, and I've always tried to do that without a big formal plan, preferably." One participant explained that, although she required reduced work hours as an accommodation, she tried and was 
able to meet her needs informally without going through the accommodation process: "I just said that I wanted to work four days a week. There was no explanation or questions why, and they're always happy to save money. It's just that I said I wanted to work an $80 \%$ schedule and they said ok. It's not an official accommodation."

Interviewees commonly mentioned resisting the accommodation process out of fear of potential impact on their jobs, like those who hesitated to disclose their disabilities at work. In some cases, people reported fearing for their job security if they requested accommodation, due to the negative stigma and stereotypes of disability. One participant explained how she feared drawing negative attention to herself in an insecure job environment by asking for accommodation: "I really didn't want any of that stuff in my employee file or anything. You know when Frodo and Sam are rushing across Mordor and the eye of Sauron keeps swooping over and they're hiding behind rocks and stuff? That was me. Just trying not to really be noticed." Another expressed her concerns about potentially problematic privacy issues related to the accommodation process, especially for those who are less comfortable about disclosing their disabilities: "My supervisor never needs to know why... That's the policy, but in practice I feel like it's very hard to do that... Not that I mind necessarily... I've been dealing with this for years, since I was a kid, so it doesn't bother me anymore, but maybe if it was something new that would have been difficult for me I think."

When participants did ask for accommodation, they reported mixed experiences and outcomes. Some interviewees reported positive experiences with the accommodation process and results. As one recounted:

When I got to my new job I was told right away that someone could come in, and they did ...And not only did they do it they did it in a really timely fashion. I was very impressed. And grateful. And there was follow-up as well, which I really appreciated. I felt like they weren't just going through the motions, they really wanted to make sure I had what I needed to perform my best.

In some cases, however, even though accommodations were granted, they had mixed results and success. One participant with hearing loss reported successfully requesting hearingrelated assistive technology for meetings but then having continuous difficulties that often made the technology unusable: "It was picking up the [university name] radio station, so I would sit through these meetings with music or conversation or commentary or whatever it was going on. I could hear it and nobody else could hear it. Sometimes I just had to turn it off because it was just impossible. They couldn't figure out a way to fix that... So even though we have assistive devices they don't always work perfectly." In this case, the workplace was willing to provide assistive technology, but they assumed that purchasing the technology was all that was required. As this participant mentioned, "I have to say I don't think anyone ever actually asked me 'is this working for you?' They just assumed it was."

Some interviewees reported negative, difficult, and stressful experiences with accommodation requests. Negative experiences tended to be associated with more "difficult" requests. People with straightforward requests like furniture or technology tended to report relatively positive experiences, but people who needed changes to work patterns or hours tended to report more negative experiences. One participant who requested both straightforward and difficult types of accommodation expressed the difference between the two in her experience: 
"The simple stuff is accommodated easily. The more difficult stuff I think there is always a fight, an unnecessary fight, and that's what I find very unfortunate. That someone has to go to some kind of war to get it done." A participant who required reduced hours as an accommodation described her struggle based on reluctance to provide this kind of flexibility: "I did have a recent experience where my doctor said 'ok she can only work so many hours,' and I was told immediately 'I don't know if you can work here anymore.' That's totally against the law." Another participant encountered similar reluctance to change the usual work patterns when she requested a change to her work arrangement. She was upset that library management had an immediate negative response to her request without speaking with her or trying to work out a mutual solution: "They denied the request immediately, on the basis of the operational needs of the problematic department. I feel that we could have sat down and laid out what each of us needed and come up with some kind of solution, but they just said no." These negative management reactions to "difficult" accommodation requests correspond with findings from $\mathrm{O}^{\prime} \mathrm{Neill}$ and Urquhart's study of library management attitudes to accommodation, which found that managers were reluctant to grant accommodation involving changes to work patterns or hours due to misunderstandings of this type of accommodation as granting special treatment to people with disabilities. ${ }^{60}$

\section{Positive Workplace Experiences}

Despite the barriers and the workplace implications of those barriers found in this study, many interview participants reported positive job experiences. These positive experiences often related to the traditional values of libraries, including a people-oriented service culture and a traditionally flexible professional work environment.

Interview participants for the most part reported a high level of job satisfaction. As one said, "Libraries are generally nice places to work, and librarians want to be nice to people and inclusive and are generally liberal and that kind of stuff." The most common themes related to positive job experiences were supportive colleagues and supervisors, some understanding of disability in the workplace, and a high level of flexibility and autonomy.

When asked what made their job experiences positive, interviewees most frequently mentioned helpful, collegial environments with strong support from colleagues and supervisors. Several mentioned that the people- and service-orientation of their workplaces translated into positive work environments. As one said, "It's a good workplace. People are very respectful, teamwork is very important here, and I find that if something is going on no matter what it is you can talk to someone and someone will help you out."

Many of the interviewees with high levels of job satisfaction also pointed to an understanding of and sympathy toward disability in their organizations. This included sympathetic supervisors who don't require justifications and explanations for disability-related issues: "My boss is good, if I have to take a mental health day, I can just email and say I'm not feeling good, I'm not coming in." Interviewees also mentioned colleagues who showed understanding through small acts of support. As one said, "I forget things quite a lot so I'm always asking my colleagues the same question over and over again, and my colleagues are super patient and always helpful with me."

Another factor in job satisfaction was the flexibility and autonomy in many academic librarian positions. Several participants mentioned autonomy in deciding on and prioritizing work as an important aspect of their work satisfaction. Some also mentioned the importance 
of flexibility in how the work gets done: "I think there's variety in how you can meet the requirements of the job, which makes it more accessible because people are going to struggle if you're expected to live up to this expectation of what it needs to look like." A few participants mentioned the importance to them of flexible work patterns, such as the ability to sometimes work from home, and of flexible work hours. As one commented, "For me it's that continued flexibility, the ability to work around the peaks and valleys of my own energy or my own pain." Most of the participants who did not have flexible work hours commented on how much having flexibility would improve their work experience.

\section{Positive Contributions of Disability}

Although the dominant cultural discourse of disability at work tends to be negative, nearly all interviewees felt that their disabilities contributed positively to their skills and ability as librarians. People mentioned a wide variety of ways that they felt their disabilities helped them in their jobs, including increased empathy for others, being more patient and understanding supervisors, the ability to bring their experiences with and knowledge of disability to improve job responsibilities like reference and instruction, and the ability to think creatively and strategically.

The most frequently mentioned way that disability contributed positively to participants' ability to do their jobs was empathy for others. Interviewees frequently mentioned that they felt their disabilities allowed them to have more empathy for others, especially for students with disabilities, and to understand other perspectives more readily. One participant with an invisible disability explained that her disability makes her more open-minded and less quick to judge based on outward appearances: "I realize that though people see me a certain way, that doesn't mean that's the same thing that's going on. So I think that's also helped me realize often that the picture I view, it doesn't mean that's what's going on." Several participants mentioned that their disabilities enable them to relate more easily to students with disabilities. As one with a mental health disability explained, "I understand the students a bit more who are kind of anxious." Other participants discussed how their disabilities enabled them to empathize more easily with other people, especially others who are marginalized, and better understand different perspectives. Some interviewees with intersecting marginalities talked about how it was difficult to tell how their disabilities could be separated in this regard from their other identities:

I'm a lesbian, and I think that experience has helped me understand, or maybe have some critical view of society, and to have some ability to empathize with other people, recognizing that we're all different I guess. Not that other peoples' experiences are like mine. But that does sort of help I think with understanding where people are coming from and so on. So I suppose the disability would have the same effect, but I'm not sure how much of that comes from being a lesbian or being a woman or having a disability.

Both participants who were in management positions felt that their disabilities helped them perform better as managers. One commented that her disability helped her understand the need to be flexible because people need to do things in different ways: "I think it's helped 
me in my leadership role. Though I like things to move along quickly, I am still able to have a lot of empathy, because I realize not everyone can do it my way, or that way." The other felt that having limits inherent in her impairment helped her to be a more understanding supervisor and more tolerant of other persons' limitations in various ways: "I think it helps me be more sympathetic to staff... I'm not a very patient person myself, and I think it probably helps me be a little more patient with people who don't think as quickly as I think."

Several participants spoke about how they were able to apply their experience with and understanding of disability to aspects of their job, which helped them be more effective. Several talked about how their disabilities helped them to be more inclusive for all students, especially in their reference and instruction. As one participant explained, "I would say in terms of my reference and my instructional style, I'm much more aware and I'm much more flexible, and I'm constantly thinking 'can every single person hear me; can every single person see me,' which has got to make it better for everyone." Another discussed how she is able to apply her knowledge of disability issues and approaches to her work to help her be a better and more inclusive instructor: "I think it helps me in my information literacy teaching for example... I think because I've done work with people with disabilities in different settings throughout my life, I've done some things about universal design, I know about universal design for learning and I can incorporate that."

Multiple interviewees felt that they were able to bring flexible thinking and creative strategies to their work as a result of their disabilities. One commented that navigating the world every day with a disability necessarily involves flexibility and creative strategies: "I think one of the reasons I'm good at reference is that I'm very flexible in my thinking, and I think that flexible thinking comes out of the disability, because you're constantly strategizing how to deal with certain issues." Another discussed how fluctuations in her disability have taught her to be more broad-minded and flexible and open to change: "Things change all the time. And that's that, so I've learned to be flexible. Things usually work themselves out, so basically there's no need to freak out about small things. It's important to look at the big picture. Steps back are normal but as long as you're still moving in a forward direction, it's all good. Things will never be perfect. Or if they are, it won't last and that's ok."

\section{Summary and Discussion}

Major goals of this study were to discover more about the work experiences of university librarians with disabilities in Canada and some of the underlying structural issues and barriers within the workplace that create difficulties for them. The results demonstrate that participants generally had positive workplace experiences with high levels of job satisfaction, especially those with supportive colleagues and supervisors, in workplaces with some awareness and understanding of disability, and with a high level of flexibility and autonomy in their jobs.

However, the results also showed that librarians with disabilities encounter barriers and difficulties in the workplace. The main barriers reported in the study were related to a lack of awareness or ill-informed view of disability, including an assumption that everyone in the workplace is nondisabled, and negative stereotypes of people with disabilities as lazy and less productive at work. Additional barriers involved the increased expectations for heavy workload, speed, and productivity in the workplace, along with the ambiguity of some library structures and priorities and the lack of effective structural supports to ensure workplace support for people with disabilities. 
These barriers had a number of impacts on university librarians with disabilities at work. The most commonly reported impact was negative reactions from colleagues and supervisors, including being uncomfortable with disability and either minimizing the experience of disability or minimizing the person with a disability. Many participants also reported some reluctance to discuss or disclose their disabilities at work due to negative past experiences with stigma or fear of negative impacts on their jobs due to negative cultural stereotypes of disability. Most participants had not fully disclosed their disabilities at work and discussed them only with a few people they trusted. Similarly, participants expressed reluctance to request legal accommodations when needed for fear of negative judgments or impacts on their jobs. Although some people had positive experiences with accommodation requests, especially for requests involving one-time purchases like furniture or straightforward physical changes, participants who needed flexible or reduced work hours or flexible work patterns reported considerable stress and difficulty and less success at having their accommodations granted.

Another goal of this study was to discover similarities or differences from existing disability studies research on the experiences of people with disabilities in other work contexts. The results substantially correspond with findings in the existing disability studies research. As was found in this study, research on the work experiences of people with disabilities in professional positions has consistently found that major barriers include a lack of understanding of disability, negative social constructions and stereotypes of disability as less productive, and the invisibility of disability within the workplace. ${ }^{61}$ Like the findings of this study, the disability studies literature on work reports that barriers for people with disabilities at work include the pressure of an efficiency-based, productivity-oriented neoliberal workplace culture, which creates assumptions in the workplace that make disability problematic due to the negative stereotypes of disability as less productive. ${ }^{62}$

This study's findings on the impacts of these barriers, especially related to disclosure and accommodation, also correspond to findings in the disability studies literature. In particular, both this study and the literature find that fear of negative work impacts and stigma makes people hesitant to disclose their disability or request accommodations at work. ${ }^{63}$ When requesting accommodation, disability studies research also reports that people with invisible disabilities or requesting more flexible work arrangements tend to have a greater struggle being granted accommodation, a lower success rate, and a greater likelihood of being accused of faking or taking advantage of the system. ${ }^{64}$

There is an apparent contradiction in this study's findings, between positive workplace experiences, supportive colleagues and supervisors, and the existence of structural barriers and workplace impacts. However, this tension also corresponds with disability studies literature, which finds that generally positive attitudes to disability tend not to correspond with disability-positive behaviors or structures. For example, employers generally express positive attitudes toward hiring people with disabilities but tend not to hire them. ${ }^{65}$ Generally supportive attitudes do not translate into equity for people with disabilities without an understanding of disability-specific issues in the workplace and specific efforts to address them through workplace policies and structures.

\section{Conclusion}

Although this study demonstrates that librarians with disabilities share some common experiences with people with disabilities working in other contexts, much more work needs to be 
done to better understand their specific experiences within libraries. This study is meant to be an initial exploration of the experiences of librarians with disabilities working in Canadian academic libraries, and it has limitations. As it is exploratory in nature, its scope is necessarily broad, and covers many aspects of participants' work experiences. All the themes found in this study warrant further in-depth research to provide a deeper and more nuanced understanding. Many areas for follow-up are suggested by the findings reported here, including specific experiences of librarians with different types of disabilities, attitudes and knowledge of disability within libraries or by library managers, factors that create positive work environments for librarians with disabilities, experiences with accommodation, and strategies used by librarians with disabilities to navigate workplace barriers. One important area for future research hinted at in the study is the intersectional nature of disability. It is clear that experiences with disability vary, and that disability may be experienced differently by people with different disabilities and with multiple overlapping areas of marginalization, such as disability and race or sexual orientation. Intersectionality and disability is a critical area requiring more research and would further connect disability with other important research on diversity and equity issues in librarianship.

Although the major barriers found in this study are related to attitudes and perceptions of disability, the disability studies literature argues that attitudes are not the only cause of discrimination against people with disabilities, and focusing too much on them risks overlooking other barriers. ${ }^{66}$ With this in mind, it would be helpful for future research to address some of the specific workplace processes, structures, and assumptions that also create barriers for librarians with disabilities. Some of these are hinted at in this study, such as hiring, promotion, supervisory, merit, and evaluation processes, as well as assumptions around decision-making speed and processes, turnaround and preparation time, and running meetings.

Since this study is interview-based and qualitative, findings are meant to describe a particular context rather than to be generalizable. It is important to note that laws, policies, and cultural attitudes to disability vary considerably by context, as do workplace cultures and expectations ${ }^{67}$ This means that the experiences of librarians with disabilities are likely to vary by country, location, type, and perhaps size of library. Future research needs to be done in different contexts to help fill in the broader picture of workplace experiences of librarians with disabilities.

When asked what would help make their work environment better, nearly all interviewees talked about more open discussion and awareness of disability in their workplaces. Disability in academic librarianship is still largely invisible; and, though many librarians are working to improve this situation, this study demonstrates that they face significant social and attitudinal barriers and need to take risks in their workplaces to do so.

A common misconception of disability in the workplace is that people ask for accommodation, which then takes care of any issues people have. As this study shows, the reality for Canadian academic librarians with disabilities is much more complicated, influenced by social and cultural views of disability and work. The traditional workplace focus on accommodation reflects the medical model of disability, which treats disability as a medical issue that belongs to an individual and should be dealt with on an individual level. This view minimizes disability: if people feel disability is only a specific person's problem, they don't need to pay attention to it. ${ }^{68}$ Improving the workplace experience for librarians with disabilities requires a valuing of differences and a broader focus on cultural and social attitudes and on structural change, rather than on individuals. 


\section{APPENDIX. Interview Questions}

1. What do you do in your job?

2. What is your library like as a workplace?

3. What employee traits are most valued at your library?

4. What effect does your disability have at work?

5. How has your disability created problems or difficulties for you at work?

6. How have you dealt with these problems or difficulties?

7. What could be changed at work to help make things easier for you?

8. How has your disability helped you as a librarian?

9. Is there anything else you'd like to add about your work experiences as an academic librarian with a disability?

\section{Notes}

1. "ACRL Board to Establish New Equity, Diversity, and Inclusion Initiative," ACRL Insider (Mar. 5, 2018), available online at www.acrl.ala.org/acrlinsider/archives/15380 [accessed 3 April 2018].

2. For example see, David James Hudson, “On 'Diversity' as Anti-Racism in Library and Information Studies: A Critique," Journal of Critical Library and Information Studies 1, no. 1 (2017): 1-36, doi:10.24242/jclis.v1i1.6; Mary Kandiuk, "Promoting Racial and Ethnic Diversity among Canadian Academic Librarians," College \& Research Libraries 75, no. 4 (2014): 492-556, doi:10.5860/crl.75.4.492; Jaena Alabi, "Racial Microaggressions in Academic Libraries: Results of a Survey of Minority and Non-Minority Librarians," Journal of Academic Librarianship 41, no. 1 (2015): 47-53, doi:10.1016/j.acalib.2014.10.008; Ione T. Damasco and Dracine Hodges, "Tenure and Promotion Experiences of Academic Librarians of Color," College E Research Libraries 73, no. 3 (2012): 279-301, doi:10.5860/ crl-244.

3. ALA Office for Research and Statistics, "Diversity Counts" (2012), 1-12, available online at www.ala. org/offices/diversity/diversitycounts/divcounts [accessed 2 March 2018]; Canadian Association of Professional Librarians, "2016 Census of Canadian Academic Librarians User Guide and Results Summary" (Toronto, 2016), available online at https://capalibrarians.org/wp/wp-content/uploads/2016/12/Census_summary_and_user_ guide_December_16_2016.pdf [accessed 2 March 2018].

4. C.G.K. Atkins, "A Cripple at a Rich Man's Gate: A Comparison of Disability, Employment and AntiDiscrimination Law in the United States and Canada," Canadian Journal of Law and Society 21, no. 2 (2006): 87-111.

5. Bally Thun, "Disability Rights Frameworks in Canada," Journal of Individual Employment Rights 12, no. 4 (2007): 351-71, doi:10.2190/IE.12.4.g.

6. Atkins, "A Cripple at a Rich Man's Gate"; Thun, "Disability Rights Frameworks in Canada."

7. Canadian Human Rights Commission, The Rights of Persons with Disabilities to Equality and Non-Discrimination: Monitoring the Implementation of the UN Convention of the Rights of Persons with Disabilities in Canada (2015), available online at https://www.chrc-ccdp.gc.ca/sites/default/files/chrc_un_crpd_report_eng.pdf [accessed 2 March 2018].

8. For example, see Sharon L. Harlan and Pamela M. Robert, "The Social Construction of Disability in Organizations," Work \& Occupations 25, no. 4 (1998): 397-435; Pamela M. Robert and Sharon L. Harlan, "Mechanisms of Disability Discrimination in Large Bureaucratic Organizations: Ascriptive Inequalities in the Workplace," Sociological Quarterly 47, no. 4 (2006): 599-630, doi:10.1111/j.1533-8525.2006.00060.x; Jana Burke et al., "Employers' Attitudes towards Hiring and Retaining People with Disabilities: A Review of the Literature," Australian Journal of Rehabilitation Counselling 19, no. 1 (2013): 21-38, doi:10.1017/jrc.2013.2; Rebecca Gewurtz and Bonnie Kirsh, "Disruption, Disbelief and Resistance: A Meta-Synthesis of Disability in the Workplace," Work 34, no. 1 (2009): 33-44, doi:10.3233/WOR-2009-0900.

9. Angela Galvan, "Soliciting Performance, Hiding Bias: Whiteness and Librarianship," In the Library with the Lead Pipe (June 3, 2015), available online at www.inthelibrarywiththeleadpipe.org/2015/soliciting-performancehiding-bias-whiteness-and-librarianship [accessed 21 February 2018].

10. Damasco and Hodges, "Tenure and Promotion Experiences of Academic Librarians of Color."

11. Maha Kumaran, "Succession Planning Process That Includes Visible Minority Librarians," Library Management 36, no. 6/7 (2015): 434-47, doi:10.1108/LM-12-2014-0138. 
12. Xiaoyin Zhang, "Library Minority Managers: Ways to Survive and to Succeed," Journal of Educational Media \& Library Sciences 39, no. 3 (2002): 227-34.

13. Mary Kandiuk, "Promoting Racial and Ethnic Diversity among Canadian Academic Librarians," College $\mathcal{E}$ Research Libraries 75, no. 4 (2014): 492-556, doi:10.5860/crl.75.4.492; Maha Kumaran and Heather Cai, "Identifying the Visible Minority Librarians in Canada: A National Survey," Evidence Based Library E Information Practice 10, no. 2 (2015), available online at https://journals.library.ualberta.ca/eblip/index.php/EBLIP/article/view/23294 [accessed 15 January 2018].

14. Jaena Alabi, "'This Actually Happened': An Analysis of Librarians' Responses to a Survey about Racial Microaggressions," Journal of Library Administration 55, no. 3 (2015): 179-91, doi:10.1080/01930826.2015.1034040; Damasco and Hodges, "Tenure and Promotion Experiences of Academic Librarians of Color"; Kandiuk, "Promoting Racial and Ethnic Diversity among Canadian Academic Librarians"; Kumaran, "Succession Planning Process That Includes Visible Minority Librarians"; Kumaran and Cai, "Identifying the Visible Minority Librarians in Canada: A National Survey"; Joyce K. Thornton, "Job Satisfaction of Librarians of African Descent Employed in ARL Academic Libraries," College E Research Libraries 61, no. 3 (2000): 217-32, doi:10.5860/crl.61.3.217; Zhang, "Library Minority Managers: Ways to Survive and to Succeed."

15. Damasco and Hodges, "Tenure and Promotion Experiences of Academic Librarians of Color"; Kandiuk, "Promoting Racial and Ethnic Diversity among Canadian Academic Librarians"; Kumaran, "Succession Planning Process That Includes Visible Minority Librarians"; Kumaran and Cai, "Identifying the Visible Minority Librarians in Canada."

16. Thornton, "Job Satisfaction of Librarians of African Descent Employed in ARL Academic Libraries"; Cynthia Preston, "Perceptions of Discriminatory Practices and Attitudes: A Survey of African American Librarians," College \& Research Libraries 59, no. 5 (1998): 433-44.

17. Alabi, "Racial Microaggressions in Academic Libraries."

18. Norda Majekodunmi, "From Recruitment to Tenure: A Reflection on Race and Culture in a Canadian Academic Library," in Aboriginal and Visible Minority Librarians: Oral Histories from Canada, eds. Deborah Lee and Mahalakshmi Kumaran (Plymouth, UK: Rowman \& Littlefield, 2014), 199-211.

19. For example, see Freeda Brook, Dave Ellenwood, and Althea Eannace Lazzaro, "In Pursuit of Antiracist Social Justice: Denaturalizing Whiteness in the Academic Library," Library Trends 64, no. 2 (2015): 246-84, doi:10.1353/lib.2015.0048; Gianmarco Visconti, "Legislation without Empathy: Race and Ethnicity in LIS," Partnership: The Canadian Journal of Library \& Information Practice \& Research 10, no. 2 (2015): 1-9; Myrna Morales, Em Claire Knowles, and Chris Bourg, "Diversity, Social Justice, and the Future of Libraries," portal: Libraries $\mathcal{E}$ the Academy 14, no. 3 (2014): 439-51, doi:10.1353/pla.2014.0017; April Hathcock, "White Librarianship in Blackface: Diversity Initiatives in LIS," In the Library with the Lead Pipe (Oct. 7, 2015), available online at www.inthelibrarywiththeleadpipe.org/2015/lis-diversity [accessed 2 March 2018]; Angela Galvan, "Soliciting Performance, Hiding Bias: Whiteness and Librarianship," In the Library with the Lead Pipe (June 3, 2015), available online at www. inthelibrarywiththeleadpipe.org/2015/soliciting-performance-hiding-bias-whiteness-and-librarianship [accessed 2 March 2018]; Hudson, "On 'Diversity' as Anti-Racism in Library and Information Studies"; Gina SchlesselmanTarango, "How Cute! Race, Gender, and Neutrality in Libraries," Partnership: The Canadian Journal of Library and Information Practice and Research 12, no. 1 (2017): 1-18, doi:10.21083/partnership.v12i1.3850.

20. Heather Hill, "Disability and Accessibility in the Library and Information Science Literature: A Content Analysis," Library \& Information Science Research 35, no. 2 (2013): 137-42, doi:10.1016/j.lisr.2012.11.002.

21. Anne-Marie O'Neill and Christine Urquhart, "Accommodating Employees with Disabilities: Perceptions of Irish Academic Library Managers," New Review of Academic Librarianship 17, no. 2 (2011): 234-58, doi:10.1080/ 13614533.2011.593852.

22. Mary E. Brown, "Invisible Debility: Attitudes toward the Underrepresented in Library Workplaces," Public Library Quarterly 34, no. 2 (2015): 124-33, doi:10.1080/01616846.2015.1036707.

23. Jodi Johnstone, "Employment of Disabled Persons in the Academic Library Environment," Australian Library Journal 54, no. 2 (2005): 156-63, doi:10.1080/00049670.2005.10721743.

24. George Warren, The Handicapped Librarian: A Study in Barriers (Metuchen, NJ: Scarecrow Press, 1979).

25. Fran Ziglar, "Being a Librarian with a Disability: Personal Reflections," Tennessee Libraries 56, no. 1 (2006).

26. Cara Barlow, "Don't Just Serve People with Disabilities: Hire Them," American Libraries 26, no. 8 (1995): $772-73$.

27. Donald Sager, "No Barriers to Service: Librarians with Disabilities," Public Libraries 37, no. 2 (1998): 109-11.

28. Alana Kumbier and Julia Starkey, "Access Is Not Problem Solving: Disability Justice and Libraries," Library Trends 64, no. 3 (2016): 468-91.

29. Kumbier and Starkey, "Access Is Not Problem Solving," 481.

30. Colin Barnes, "Understanding the Social Model of Disability: Past, Present and Future," in Routledge 
Handbook of Disability Studies, eds. Carol Watson, Nick Roulstone, and Alan Thomas (London: Routledge, 2012), 12-29; Fiona Kumari Campbell, Contours of Ableism: The Production of Disability and Abledness (Houndmills, UK: Palgrave Macmillan, 2009).

31. Stephanie Wilton and Robert Scheur, "Towards Socio-Spatial Inclusion? Disabled People, Neoliberalism and the Contemporary Labor Market," Area 38, no. 2 (2006): 186-95; E. Jammaers, P. Zanoni, and S. Hardonk, "Constructing Positive Identities in Ableist Workplaces: Disabled Employees Discursive Practices Engaging with the Discourse of Lower Productivity," Human Relations 69, no. 6 (2016): 1365-86, doi:10.1177/0018726715612901; Marianne Pieper and Jamal Haji Mohammadi, "Ableism and Racism: Barriers in the Labour Market," Canadian Journal of Disability Studies 3, no. 1 (2014): 65-92; Burke et al., "Employers' Attitudes towards Hiring and Retaining People with Disabilities."

32. Burke et al., "Employers' Attitudes towards Hiring and Retaining People with Disabilities"; Lori Anderson Snyder et al., "Perceptions of Discrimination and Justice among Employees with Disabilities," Employee Responsibilities and Rights Journal 22, no. 1 (2010): 5-19, doi:10.1007/s10672-009-9107-5.

33. Angus Duff and John Ferguson, "Disability and the Professional Accountant: Insights from Oral Histories," Accounting, Auditing, and Accountability Journal 25, no. 1 (2011): 71-101, doi:10.1108/09513571211191752; Paul Harpur, "Naming, Blaming and Claiming Ablism: The Lived Experiences of Lawyers and Advocates with Disabilities," Disability \& Society 29, no. 8 (2014): 1234-47, doi:10.1080/09687599.2014.923749; Snyder et al., "Perceptions of Discrimination and Justice among Employees with Disabilities."

34. Robert and Harlan, "Mechanisms of Disability Discrimination in Large Bureaucratic Organizations"; A. Roulstone and J. Williams, "Being Disabled, Being a Manager: 'Glass Partitions' and Conditional Identities in the Contemporary Workplace," Disability \& Society 29, no. 1 (2014): 16-29, doi:10.1080/09687599.2013.764280; Dana Wilson-Kovacs et al., "Just Because You Can Get a Wheelchair in the Building Doesn't Necessarily Mean That You Can Still Participate': Barriers to the Career Advancement of Disabled Professionals," Disability \& Society 23, no. 7 (2008): 705-17, doi:10.1080/09687590802469198.

35. Cheryl L. Shigaki et al., "Disability on Campus: A Perspective from Faculty and Staff," Work 42, no. 4 (2012): 559-71, doi:10.3233/WOR-2012-1409; Sarah von Schrader, Valerie Malzer, and Susanne Bruyere, "Perspectives on Disability Disclosure: The Importance of Employer Practices and Workplace Climate," Employee Responsibilities and Rights Journal 26, no. 4 (2014): 237-55, doi:10.1007/s10672-013-9227-9.

36. Harlan and Robert, "The Social Construction of Disability in Organizations."

37. Barnes, "Understanding the Social Model of Disability."

38. Barnes, "Understanding the Social Model of Disability."

39. Dan Goodley, Disability Studies: An Interdisciplinary Introduction (Newbury Park, CA: Sage Publications, 2010).

40. Campbell, Contours of Ableism.

41. Goodley, Disability Studies.

42. Campbell, Contours of Ableism.

43. Michael Oliver and Colin Barnes, The New Politics of Disablement (Houndmills, UK: Palgrave Macmillan, 2012).

44. Harlan and Robert, "The Social Construction of Disability in Organizations."

45. Meg Braedley, Susan Luxton, "Competing Philosophies: Neoliberalism and the Challenges of Everyday Life," in Neoliberalism and Everyday Life, eds. Susan Luxton and Meg Braedley (Montreal, Quebec: McGill-Queens University Press, 2010), 3-21; Jammaers, Zanoni, and Hardonk, "Constructing Positive Identities in Ableist Workplaces"; Wilton and Scheur, "Towards Socio-Spatial Inclusion?"

46. Andrea Vick, "Living and Working Precariously with an Episodic Disability: Barriers in the Canadian Context," Canadian Journal of Disability Studies 3, no. 3 (2014): 4.

47. Bill Hughes, "Disabled People as Counterfeit Citizens: The Politics of Resentment Past and Present," Disability \& Society 30, no. 7 (2015): 991-1004, doi:10.1080/09687599.2015.1066664; Jammaers, Zanoni, and Hardonk, "Constructing Positive Identities in Ableist Workplaces"; Wilton and Scheur, "Towards Socio-Spatial Inclusion?"

48. Jammaers, Zanoni, and Hardonk, "Constructing Positive Identities in Ableist Workplaces," 1368.

49. Martin Turcotte, "Persons with Disabilities and Employment," Insights on Canadian Society, no. 75-006 (2014): 15, available online at www.statcan.gc.ca/pub/75-006-x/2014001/article/14115-eng.pdf [accessed 21 February 2018].

50. David Zarifa, David Walters, and Brad Seward, "The Earnings and Employment Outcomes of the 2005 Cohort of Canadian Postsecondary Graduates with Disabilities," Canadian Review of Sociology 52, no. 4 (2015): 343-76, doi:10.1111/cars.12082.

51. Susan Wendell, The Rejected Body: Feminist Philosophical Reflections on Disability (New York: Routledge, 1996), 23. 
52. Wendell, The Rejected Body, 24.

53. See Egon G. Guba, "Criteria for Assessing the Trustworthiness of Naturalistic Inquiries," Educational Technology Research and Development 29, no. 2 (1981): 75-91.

54. Johnny Saldana, The Coding Manual for Qualitative Researchers, 3rd ed. (London, Thousand Oaks, CA: Sage Publications, 2016).

55. Guba, "Criteria for Assessing the Trustworthiness of Naturalistic Inquiries"; Laura Krefting, "Rigor in Qualitative Research: The Assessment of Trustworthiness," American Journal of Occupational Therapy 45, no. 3 (1991): 214-22; Sharon M. Ravitch and Nicole M. Carl, Qualitative Research: Bridging the Conceptual, Theoretical and Methodological (London, Thousand Oaks, CA: Sage Publications, 2016).

56. Guba, "Criteria for Assessing the Trustworthiness of Naturalistic Inquiries."

57. Ravitch and Carl, Qualitative Research, 63.

58. Harlan and Robert, "The Social Construction of Disability in Organizations."

59. Wendell, The Rejected Body, 37.

60. O'Neill and Urquhart, "Accommodating Employees with Disabilities."

61. Snyder et al., "Perceptions of Discrimination and Justice among Employees with Disabilities"; Duff and Ferguson, "Disability and the Professional Accountant."

62. Roulstone and Williams, "Being Disabled, Being a Manager."

63. Shigaki et al., "Disability on Campus"; von Schrader, Malzer, and Bruyere, "Perspectives on Disability Disclosure."144

64. Harlan and Robert, "The Social Construction of Disability in Organizations."

65. Burke et al., "Employers' Attitudes towards Hiring and Retaining People with Disabilities."

66. Bob Pease, Undoing Privilege: Unearned Advantage in a Divided World (London: Zed Books, 2010), 152.

67. Lisa Schur et al., "Is Disability Disabling in All Workplaces? Workplace Disparities and Corporate Culture," Industrial Relations 48, no. 3 (2009): 381-410, doi:10.1111/j.1468-232X.2009.00565.x.

68. Susan L. Gabel and Maja Miskovic, "Discourse and the Containment of Disability in Higher Education: An Institutional Analysis," Disability \& Society 29, no. 7 (2014): 1145-58, doi:10.1080/09687599.2014.910109. 